Onieva López, J.L. (2016). Estrategias didácticas y recomendaciones para la defensa oral de los Trabajos Fin de Grado y Fin de Máster. Revista Electrónica Interuniversitaria de Formación del Profesorado, 19(3), 185-198.

\title{
Estrategias didácticas y recomendaciones para la defensa oral de los Trabajos Fin de Grado y Fin de Máster
}

\author{
Juan Lucas Onieva López \\ Universidad de Málaga
}

\section{Resumen}

La defensa oral de los TFG y TFM será el tema que desarrollaremos en este artículo y que, con el objetivo de ayudar al alumnado y al profesorado sobre esta cuestión, analizaremos las diferentes planillas de evaluación que utilizan las universidades y las que recomiendan diferentes especialistas. También consideraremos aquellos sentimientos que ahogan a los estudiantes en este tipo de escenarios y propondremos pensamientos, ideas y estrategias para realizar una buena exposición. Para ello, ofreceremos una serie de recursos y propuestas para que los alumnos y docentes afronten con éxito la defensa de este tipo de trabajos.

\section{Palabras clave}

Comunicación verbal; evaluación; didáctica; enseñanza superior.

\section{Didactic strategies and recommendations for the oral defence of bachelor and masters dissertation}

\begin{abstract}
The oral defence of BD and MD will be the topic developed in this article. With the main objective of helping the students and teachers about this topic, we will make an analysis of
\end{abstract}

Contacto

Juan Lucas Oneiva López, juanlucas98@gmail.com. Departamento de didáctica de la Lengua y la Literatura de la Universidad de Málaga, Universidad de Málaga. España 
the different evaluation rubrics used by universities and those recommended by different specialists. We will also considered those feelings that suffocate the students in this kind of scenario, and we will propose thoughts, ideas and strategies to accomplish a good presentation. To achieve this goal, we will offer a series of resources and proposals for students and teachers to help them to face the defence of this type of work successfully.

\section{Key words}

Verbal communication; evaluation; didactics; university studies.

\section{La expresión oral en los trabajos Fin de Grado y Fin de Máster}

Recientemente se ha celebrado en Bilbao el I Congreso Interuniversitario del Trabajo Fin de Grado (TFG) con el objetivo de establecer un marco común de reflexión donde compartir experiencias, inquietudes y dudas. La creación de este tipo de eventos tiene su origen en la preocupación e inminente necesidad de los docentes universitarios en capacitarse para impartir esta nueva asignatura, que implica un trabajo de tutorización y evaluación diferente al del resto de asignaturas que se imparten comúnmente.

Al coexistir diferentes modelos o formas de trabajar y evaluar los Trabajos Fin de Grado y Fin de Máster, se posibilita que cada universidad disponga de autonomía para singularizarlos y adecuarlos a sus propios intereses, y al de cada titulación. Para Ferrer (2013) el TFG tiene una doble función, la primera es para los alumnos, los cuales tienen la posibilidad de investigar y profundizar en un tema novedoso o de interés personal con el que acabar sus estudios y convertirse en un profesional en su área, posicionándose y ofreciendo un servicio o una alternativa a una cuestión o necesidad a través de un proyecto. En cambio, para el profesorado, el TFG es un nuevo reto, un desafío en el que deberá guiar a sus alumnos, ayudándolos a investigar, crear, producir, planificar y diseñar nuevas ideas, programas, empresas e iniciativas para proyectarse personal y profesionalmente. A diferencia del Trabajo Fin de Máster (TFM), según Ferrer, el TFG es mucho más generalista y no implica que el estudiante deba especializarse profesionalmente con su trabajo, además, el nivel de profundización es medio y está orientado a un proceso o producto para la inserción laboral. En cambio, el TFM está más encauzado a la creación de un producto o una mejora para un ámbito profesional concreto.

Los TFG y TFM son evaluados por un tribunal que suele estar formado por profesores de la facultad, pudiendo estar entre ellos los propios tutores de los alumnos. En una primera fase se valora el trabajo escrito a partir de una serie de criterios establecidos por la facultad o la especialidad. En la segunda fase, los alumnos deberán defender oralmente ante dicho tribunal su trabajo, no solo exponiéndolo sino también respondiendo a las preguntas que les hagan oportunamente. En esta defensa pública se valora la presentación y si los alumnos han adquirido las competencias generales y específicas de su especialidad.

Por nuestra experiencia, hemos podido evidenciar cómo mediocres exposiciones o defensas orales de algunos estudiantes no se correspondían con la buena calidad de sus trabajos escritos. Creemos que parte del problema radica en la falta de recursos, habilidades y estrategias por parte de los estudiantes para afrontar este tipo de experiencias. Para Vilà (2005), a pesar de que los alumnos están en constante diálogo con 
su entorno y aprenden a hablar de forma natural, no acaban de pensar y de expresarse en un registro mas formal o académico, como en estos casos. El motivo, según la autora, es que el profesorado o la universidad no se ha preocupado de preparar a los estudiantes para realizar exposiciones o defensas orales de forma exitosa. El origen del problema, según Villanueva (2013), es que los alumnos llegan a la universidad sin haber adquirido las estrategias necesarias sobre la expresión oral. Por ello, considera necesario la existencia de una asignatura obligatoria a lo largo de la carrera universitaria en la que se trabaje esta competencia y así, la universidad no dé por hecho que los alumnos ya la han adquirido en secundaria.

\section{La precaria formación del alumnado en la expresión oral}

Actualmente, los contextos escolares en España a diferencia de otros países carecen de una tradición pedagógica, didáctica y reflexiva de la oralidad, por lo que hay una casi total ausencia formativa de la expresión oral en las aulas desde la educación infantil. Este pensamiento de Pinilla (2012), es el mismo que expresaban casi diez años atrás autoras como Recasens (2003), según la cual, la programación en las escuelas desde primaria desatiende de forma específica todo lo relacionado con la expresión oral. Los tres principales motivos son, según la autora: porque la gramática tiene una tradición muy arraigada; se presupone que los alumnos aprenden a hablar y a escuchar de forma natural; y porque es mas cómodo y fácil para el maestro que los estudiantes aprendan a leer que a dialogar en el aula. De igual forma, el método de enseñanza tradicional ha influido negativamente en la formación del alumnado respecto a la expresión oral ya que, exceptuando la etapa de educación infantil, el maestro es el único que suele comunicarse oralmente en el aula mientras pide a sus alumnos que se mantengan permanentemente en silencio, siendo el único que puede hablar mientras sus estudiantes escriben y leen (Villanueva, 2013). Villanueva también critica que, si bien para el aprendizaje de una segunda lengua se realizan exámenes orales y se dedica gran parte del tiempo en el aula a hablar en dicho idioma, con la lengua materna se obvia la importancia de la expresión oral y se le acaba dando prioridad a la escritura y a la lectura.

Otros motivos que influyen de manera directa y negativa en la enseñanza y evaluación de la expresión oral son, según Vilà (2005), ciertas creencias erróneas del profesorado. Una de ellas es, que se tiende a pensar que los estudiantes aprenden a expresarse oralmente de forma natural al estar en constante diálogo con sus familiares y amigos. Pero realmente esto no implica que estén aprendiendo a expresarse en diferentes registros, ya que, por ejemplo, bajo ese entorno difícilmente lograrán aprender a debatir o a saber escuchar. Además, la autora también critica que gran parte del profesorado tiende a improvisar actividades de expresión oral al trabajarlas en el aula, sin una explicación previa a los estudiantes sobre cómo, por ejemplo, realizar debates, mesas redondas o exposiciones, y sin tampoco explicarles cómo se les evaluará y bajo qué criterios.

Consecuentemente, y en parte por estos motivos, los alumnos no suelen dar importancia a la expresión oral. Además, gran parte de ellos sienten mucha vergüenza al compartir sus ideas, sentimientos y opiniones públicamente, y es que ni en primaria ni en secundaria se les ayuda adecuadamente a afrontar esos pensamientos y emociones negativas. Probablemente, la falta de formación del alumnado universitario que va a ser profesor en 
primaria y secundaria condiciona las deficientes capacidades y habilidades de esos futuros docentes para promover y fomentar la expresión oral en sus estudiantes.

A la pregunta de si es suficiente el aprendizaje sobre la expresión verbal y gestual que reciben los alumnos de forma natural en su entorno más cercano, Cassany (1994) afirma que aunque pasamos el $80 \%$ de nuestro tiempo comunicándonos, y siendo la comunicación oral mucho más practicada que la escrita, no acabamos por aprender a hablar y a cambiar de registros, ni siquiera a escuchar adecuadamente. Según un estudio de Paul T. Rankin, en Gauquelín (1982), dedicamos un $45 \%$ de nuestro tiempo profesional a escuchar, un 30\% a hablar, un $16 \%$ a leer, y un $9 \%$ a escribir. Casi la mitad del tiempo estamos escuchando, pero no se nos enseña a hacerlo adecuadamente para mejorar la comunicación con los demás. Además de la escucha, otro aspecto importante y necesario para mejorar la expresión oral es la actitud. En este sentido quisiéramos destacar la matriz que propone Cebreiros (2012) en la figura 1, en la que se puede encuadrar casi cualquier persona. Para el autor, indiferentemente de las aptitudes, cualquiera puede ser un buen comunicador si su actitud es la adecuada y tiene una mentalidad de cambio y de mejora (un "motor", como él lo llama). $Y$ es que tener una alta autoestima y confianza en uno mismo es esencial para comunicarse eficazmente, y si además esa persona está bien formada puede llegar a ser lo que el autor define como un líder. Por ejemplo, cuando un estudiante hace una exposición o defiende una idea de forma estimulante y motivadora, evidencia que es una persona que confía en sí misma y que posee una alta autoestima, y por ello los que le escuchan le prestarán mucha mas atención. En cambio, un alumno pesimista e inseguro difícilmente podrá transmitir adecuadamente sus ideas y pensamientos, por muy buenas aptitudes que tenga. Además, si dejamos de otorgarle mas importancia de la que merece a la opinión de los demás logramos confiar más en nosotros mismos, acaparando la atención de aquellas personas que nos escuchan.

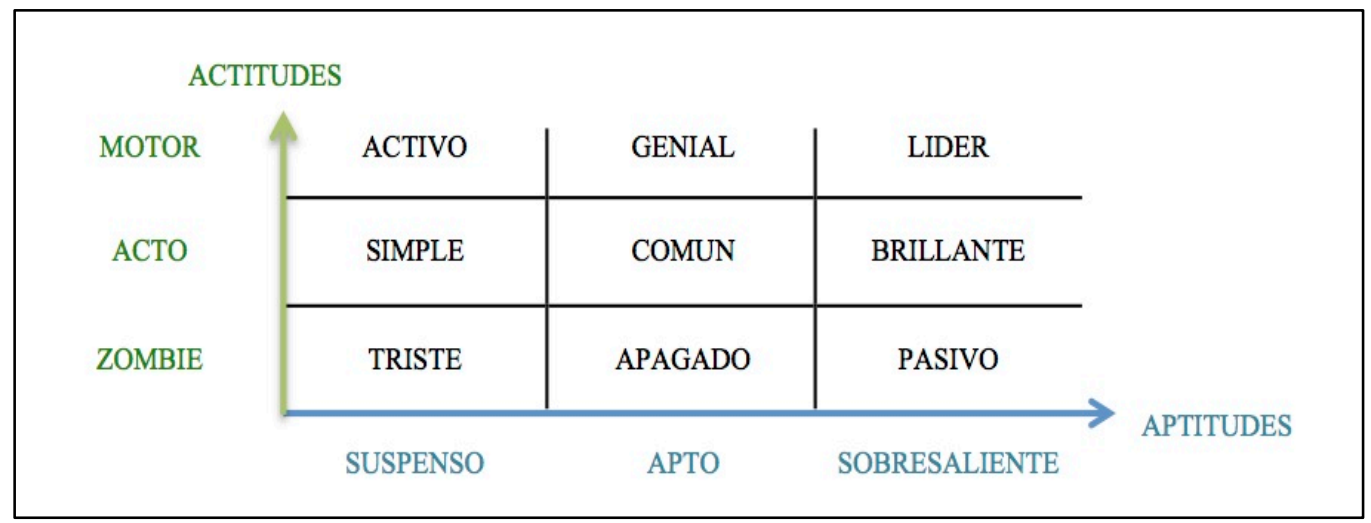

Figura 1. "Matriz de Cebre"

La actitud se suele reflejar de forma mas evidente cuando nos expresarnos oralmente. Prueba de ello es que, según Carnegie (2011), cuando nos relacionamos con otras personas solemos valorarlas y clasificarlas teniendo en cuenta su aspecto físico, la forma de vestir, su profesión, sus hobbies o los temas sobre los que conversan, pero este tipo de información que recibimos y analizamos pueden darnos una percepción errónea de ellas. Para el autor, 
existe un elemento con el que difícilmente nos podremos equivocar al valorar a otras personas, y es cuando se expresa oralmente, no importando tanto lo que dicen sino el cómo lo dicen. De manera que el tono, el ritmo, las pausas o el volumen serán aspectos de la comunicación que nos darán información clara y real de lo que siente y piensa la persona cuando se expresa. Según la regla de Mehrabian, cuando una persona se está expresando, el $55 \%$ de la información que transmite se le atribuye a los signos visuales, el $38 \%$ a las características vocales y un $7 \%$ a lo que se dice. Es decir, que en una exposición como la del TFG o TFM no solo hay una mera transmisión de información, sino que el estudiante ha de ser consciente que también está comunicando emociones e ideas con su cuerpo y su voz, captándose detalles de los cuales ni siquiera él es consciente.

La mirada, por ejemplo, tiene también una gran importancia en el proceso de comunicación. Según Knapp (2010), tendemos a fijar la mirada de media en nuestro interlocutor un $40 \%$ si estamos hablando, y un $60 \%$ al escuchar, con unos límites entre el 8 y el $73 \%$. De manera que, para que haya una buena comunicación debemos interactuar con nuestro oyente, tanto si estamos hablando como si tenemos una actitud más pasiva como público, de ahí lo importante que es saber escuchar. $\mathrm{Y}$ es que los ojos son un elemento crucial en la comunicación, pues al mirar a alguien que nos habla le estamos indicando qué interés nos despierta, qué pensamos y qué opinamos sobre lo que dice y lo que nos transmite (Vallejo-Nágera, 2007). Este aspecto es muy importante para el estudiante que realiza la defensa de su TFG o TFM, por ello solemos aconsejarles que miren a los diferentes miembros del tribunal para captar su atención y así lograr transmitir el entusiasmo y la confianza que sienten por su trabajo. De no hacerlo, bajando la mirada constantemente o mirando la mayor parte del tiempo las imágenes que utiliza para su presentación, sería un claro indicio de inseguridad, temor o desconfianza. El hecho de que los miembros del tribunal no miren al estudiante que está defendiendo su TFG también influye negativamente y dificulta la comunicación, ya que puede dar la sensación de falta de interés.

Por todo ello, tanto profesores como estudiantes deben esforzarse por establecer una muy buena comunicación y facilitarse el trabajo mutuamente. Una mirada sincera de interés por parte de los miembros del tribunal (asintiendo de vez en cuando, por ejemplo), o los estudiantes mirando a los profesores que los evalúan unos segundos a cada uno, son ejemplos que ayudarán a mantener la atención de ambos en un momento tan importante para el alumno como es la defensa de su trabajo de fin de estudios. A continuación, analizaremos diferentes aspectos de la evaluación oral de los TFG y TFM, concretando cuál debe ser el objetivo del tribunal y el de los estudiantes, así como qué tipo de rúbricas o sistemas de evaluaciones se han llevado a cabo en diferentes universidades y especialidades, y cuáles son las más recomendables.

\section{Dimensiones de la evaluación oral}

El día de la defensa del TFG o TFM el estudiante debe tener muy claro cuál es su objetivo, y en este sentido hemos utilizado la cita del escritor estadounidense William Arthur Ward, cuando decía: «El educador mediocre, habla. El buen educador, explica. El educador superior, demuestra. El gran educador, inspira». Para esta situación lo que se espera de los estudiantes es que demuestren que, por ejemplo, poseen las competencias esperadas y que 
están capacitados para desempeñar la labor profesional para la que han sido formados. Para ello, el tribunal deberá evaluar a los alumnos a través de diferentes instrumentos y valorar si han logrado o no asimilar las competencias generales y específicas establecidas en el programa de su grado o máster, por lo que no solo se deberá tener en cuenta si han adquirido conocimientos. Es decir, se evaluará no solo el trabajo que los estudiantes presentan sino también el aprendizaje y la madurez que han generado a lo largo de sus años de estudio en la universidad. "Se trata de que los docentes busquen y aprecien el valor individual de cada estudiante" (Bain, 2007: 85). Los alumnos han de tener claro que en la defensa de su trabajo no se les pretende juzgar o penalizar por los errores que cometan, sino que el único interés del tribunal es el de conocer, por ejemplo, cuáles son sus inquietudes y proyectos futuros en relación a su especialidad, así como si poseen las habilidades y competencias necesarias para desempeñarse profesionalmente. $Y$ esta información, respecto a su formación, ha de aparecer de forma clara y sencilla tanto en su trabajo escrito como en la exposición oral. Por ejemplo, destacando aspectos que tengan que ver con el aprendizaje de nuevas capacidades, el empleo de las nuevas tecnologías, la comprensión y la aplicación lógica y razonada de su profesión, así como sus inquietudes y proyectos futuros. Para ello, el alumno deberá sobresalir en su exposición por su capacidad de síntesis, su grado de madurez, su inventiva y creatividad, así como por su voluntad por convertirse en un excelente profesional de su especialidad. Una excelente presentación oral de la defensa del TFG o TFM permitirá al estudiante, no solo obtener una buena calificación, sino también demostrar la calidad de su trabajo y su nivel de compromiso con su formación. De esta manera, podrá diferenciarse del resto de alumnos, de ahí que la exposición oral sea un importante valor añadido al trabajo escrito (Blanco, 2009).

Evaluar la expresión oral de los estudiantes en las defensas de los TFG y TFM no es sencillo. Uno de los motivos por los cuales algunas exposiciones no han llegado a estar a la altura de sus correspondientes trabajos escritos es porque los alumnos no han logrado comprender los criterios establecidos en la planilla o rúbrica de evaluación. Probablemente porque no han recibido formación al respecto. Además, la mayor parte de las evaluaciones de expresión oral a las que hemos tenido acceso proponen un tipo de evaluación basada en listas de cotejo o rejillas, junto con una valoración positiva/negativa de la exposición. Esto es insuficiente para algunos autores como García-Debanc (1999, en Pinilla, 2012), según el cual, de esta manera se evalúa solo una parte de la actividad discursiva del alumno, y no su esencia. Este tipo de evaluación, según Pinilla (2012), no es ni democrática ni participativa, porque a pesar de su importancia no ha sido consensuada con los estudiantes para ayudarles en su aprendizaje y evaluación. De esta manera, los alumnos no logran entender ni comprender exactamente cómo han de incorporar a sus exposiciones los criterios de evaluación que se les exigen.

Para evaluar de forma objetiva la expresión oral de los estudiantes que defienden sus TFG y TFM durante un máximo de 15 o 20 minutos, es necesario contar con criterios e instrumentos de evaluación adecuados. Al respecto, Pinilla (2012) propone tres niveles de valoración: el lingüístico (pronunciación, entonación, voz articulación, ritmo, pausas, silencios); el pragmático (contexto, discurso, actitud, coherencia, propósito); y la concepción discursiva (gestos, movimientos, mirada, posturas). Por otro lado, Jaume-i-Capó (2012) propone evaluar también aspectos como el entusiasmo, el uso del tiempo, el empleo de imágenes y la creatividad, entre otros. Otro tipo de indicadores son los expuestos por 
Blanco (2009), para la cual hay que valorar en las exposiciones si los estudiantes saben expresar ideas con claridad, convencer con sus palabras, analizar, sintetizar, escuchar y desarrollar discursiva y ordenadamente sus pensamientos, así como si son capaces de revisar y optimizar el discurso en un tiempo determinado. Como muestra de los instrumentos que se emplean para evaluar la expresión oral en las universidades españolas expondremos dos ejemplos.

El primero está tomado de Ferrer (2013) y corresponde a la Facultad de Ciencias del Deporte de la UCLM, donde la defensa oral tiene un valor total del $40 \%$ de la nota del TFG. Sus criterios son:

- Claridad y precisión de la presentación pública mediante las TIC. (8\%)

- Demostración de dominio en el uso del lenguaje disciplinar de la temática. (8\%)

- Habilidad y dominio del lenguaje verbal (muletillas, lapsus, reiteraciones). (4\%)

- Habilidad gestual y dominio del espacio durante la exposición. (4\%)

- Distribución del tiempo de la exposición. (4\%)

- Resolución, concreción y exactitud de las respuestas a las preguntas hechas por el tribunal. (12\%)

El segundo ejemplo es la figura 2, que se ha empleado en los TFG y TFM del Grado de Educación infantil y primaria de la UMA, así como para el Master de Profesorado de Secundaria de la Especialidad Economía y Empresa de la Universidad de Zaragoza. En esta rúbrica se valora la expresión oral con un $20 \%$ del total de la nota. Como podemos comprobar ambas tienen muchos puntos en común.

\begin{tabular}{|l|l|c|c|}
\hline C. Competencias de comunicación oral (20 \%) & Peso & Puntuación \\
\hline Capacidad de exposición oral & $\begin{array}{l}\text {-Dominio y comprensión del tema. } \\
\text {-Calidad de la presentación gráfica (en su caso). } \\
\text {-Claridad, ritmo y organización de la exposición. } \\
\text {-Uso del lenguaje corporal y de la voz. }\end{array}$ & $\begin{array}{c}\text { Hasta } 8 \\
\text { puntos }\end{array}$ & \\
\hline Capacidad de síntesis & $\begin{array}{l}\text {-Selección de información clave } \\
\text {-Cumplimiento de los tiempos establecidos }\end{array}$ & $\begin{array}{c}\text { Hasta } 6 \\
\text { puntos }\end{array}$ & \\
\hline $\begin{array}{l}\text { Respuesta a preguntas y } \\
\text { comentarios }\end{array}$ & $\begin{array}{l}\text { Adecuada y pertinente argumentación ante las preguntas y } \\
\text { comentarios de los y las miembros de la Comisión Evaluadora }\end{array}$ & $\begin{array}{c}\text { Hasta } 6 \\
\text { puntos }\end{array}$ & \\
\hline Observaciones: & \multicolumn{2}{|l|}{} \\
\hline
\end{tabular}

Figura 2. Evaluación de la expresión oral (Universidad de Málaga y Universidad de Zaragoza)

Además de un adecuado instrumento de evaluación, consideramos que lo más importante es que los estudiantes, previamente a la defensa de sus TFG y TFM, sean formados respecto al significado y los criterios bajo los cuales serán evaluados. Pero aprender a realizar una buena exposición o defensa de un trabajo no se logra con un par de conferencias o con clases intensivas. Es este punto sería necesario retomar la propuesta de Villanueva (2013), que reclamaba la necesidad de impartir en la universidad una asignatura que ayude a los estudiantes a expresarse oralmente de forma sobresaliente, de acuerdo con su especialidad, y que debería ser impartida en gran parte por profesionales de cada área que tengan una dilatada experiencia y puedan ejemplificar de forma práctica su aplicación. Además, debería implantarse durante el primer curso académico y ser ofrecida teniendo en cuenta las 
diferentes asignaturas y su implicación con la práctica. Por ejemplo, un futuro profesor de primaria debería recibir formación de logopedas, para cuidar su voz como herramienta de trabajo; de oradores, que saben cómo mantener la atención de la audiencia y han aprendido a superar el miedo escénico; de cuentacuentos, para hacer más didácticas, lúdicas y motivadoras las clases; así como de periodistas y locutores de radio. Junto a esta asignatura siempre es necesario seguir trabajando con los estudiantes, tanto en clase como en cursos de manera continuada, los diferentes aspectos de la expresión oral y gestual relacionados con su futura carrera. $Y$ es que, pocas son las profesiones en las que no es necesario que las personas sean hábiles y sobresalientes comunicadoras.

\section{Aspectos que dificultan la expresión oral}

Realizar actividades tales como cantar, tocar un instrumento, dar una charla o exponer un tema ante un público suele generar en la persona que los realiza diferentes síntomas, como nerviosismo, ansiedad y estrés. Según Cester (2013), partiendo de una investigación realizada entre jóvenes intérpretes, los síntomas más frecuentes que padecían los estudiantes al estar ante un público son: el miedo a fallar o a equivocarse (en un $85 \%$ de ellos), temblores (61\%), aceleración cardíaca (59\%), sudores (54\%), así como las manos frías y excesiva preocupación por la gente (43\%). La autora divide los posibles síntomas en tres grupos: los cognitivos (vergüenza, falta de concentración y lapsus); los emocionales (frustración, miedo y ansiedad); y los conductuales (temblores, no mirar al público, pasear sin parar de moverse y rigidez muscular). Teniendo en cuenta que cada persona sufre de diferente manera la ansiedad y el estrés al realizar una actividad ante un numeroso grupo de personas, tratar de minimizarlo no es tarea fácil ni tampoco se logra con poco entrenamiento. A continuación, vamos a detallar las que pensamos son las principales dificultades que limitan una adecuada exposición oral.

a) La baja autoestima.

Nos referimos al sentido de valía que tiene la persona de sí misma, lo que implica una mayor consideración, aprecio o valoración de la propia persona y la aceptación de lo que es a pesar de las limitaciones o habilidades que posea en comparación con los demás. De manera que para minimizar los efectos negativos de la baja autoestima es necesario que el estudiante sea consciente de sus posibilidades así como de sus limitaciones, de esta manera estará más preparado para afrontar y superar las dificultades que vaya encontrando personal y profesionalmente. Según Cester (2013), solemos pensar que son las situaciones, las personas o el ambiente los que nos afectan e influyen negativamente. Por ejemplo, la defensa oral de un TFG o TFM no creará ansiedad o estrés a partir de la interpretación que hacemos de lo que implicará dar la charla. Al imaginarse el estudiante en esa situación, puede tender a pensar que, por ejemplo, puede equivocarse, o que no interesará, que lo hará mal, que aburrirá al tribunal, o que se reirán de ellos. Estos y otros muchos pensamientos irracionales se suelen agolpar en sus mentes. Por ello, para comenzar a superar esta desagradable sensación es necesario ayudarlos a cambiar esos pensamientos negativos por otros mas racionales, que los ayuden a pensar de manera más positiva y realista. Si un alumno se imagina que lo va a hacer mal y se siente angustiado porque cree que el tribunal no sabrá valorar su trabajo, que no le interesará y que se aburrirá, entonces eso será exactamente lo que ocurrirá (Burns, 2006). Por ello, es necesario reflexionar sobre 
los motivos que provocan ese estado de ansiedad, y encontrar aquellos pensamientos que inhiben su rendimiento (Blanco, 2009), no tratando de controlarlos, sino de cambiarlos.

b) El estrés.

Ha habido estudiantes que en las presentaciones de sus TFG y TFM han padecido ciertos síntomas físicos como el enrojecimiento de su piel, y tras finalizar su exposición han desaparecido. Una persona insegura y, consecuentemente con baja autoestima, será más propensa a sufrir de estrés que otra con mas confianza en sí misma. Por ello, para controlar este problema es necesario que el estudiante practique sus exposiciones y piense que con voluntad, actitud positiva, seguridad y una buena predisposición a equivocarse y a aprender de sus errores, logrará superarlo.

c) La vergüenza y el sentido del ridículo.

El sentido del ridículo no es un sentimiento exclusivamente sexual o social, sino que está relacionado con la minusvaloración que se tiene de uno, es un avergonzarse ante sí mismo, como una vergüenza ante los demás (Scheler, 2004). Este sentimiento se agrava cuando la persona comienza a pensar que no es lo suficientemente bueno o buena (Brown, 2010) para, en nuestro caso, exponer un TFG o TFM de forma sobresaliente. También es frecuente que a muchos alumnos les preocupe lo que otros puedan pensar de ellos, pero lo alarmante es cuando se dejan controlar por ese temor, por la valoración negativa que otros hagan de ellos, por la aprobación ajena y el temor al fracaso. Según Girodo (1997), esta excesiva preocupación por controlar la impresión que se da a los demás es lo que realmente perjudica la capacidad de una persona de ser espontánea y expresiva. Por ello, es importante que aprendamos a dotar del valor preciso las opiniones ajenas, y evitar así que un alto sentido del ridículo nos perjudique, entendiendo por sentido del ridículo "que la persona está muy pendiente y preocupada por no hacer algo inconveniente en presencia de los demás" (Vallejo-Nágera, 2007: 255).

\section{Propuesta para una adecuada exposición oral de los TFG y TFM}

Para realizar una presentación sobresaliente es necesario, según Blanco (2009), que los estudiantes muestren que tienen capacidad de aprendizaje autónomo, que saben manejar de forma eficaz y adecuada diferentes herramientas y métodos de comunicación, y que además controlan de forma eficaz diferentes recursos de expresión verbal y no verbal. Partiendo de esta idea, vamos a exponer nuestra propuesta dividiéndola en tres fases:

1) Fase de preparación de la exposición.

Una de las recomendaciones que hacemos a nuestros estudiantes es que, partiendo de que nadie mejor que ellos conocen el trabajo que defenderán, han de preguntarse ¿qué quiere o necesita saber el tribunal? Para ello, es importante que conozcan los criterios bajo los cuales se les evaluará. Teniendo en cuenta que el alumno dispondrá de un tiempo establecido para exponer toda aquella información que considere relevante y que está establecido por la especialidad, deberá ser consciente de si al preparar su exposición le está resultando aburrida o poco interesante, bien porque hay demasiada información o carece de atractivo. Lo mismo que el estudiante está sintiendo mientras organiza y plantea su trabajo es lo que transmitirá en la exposición. Por ello, en la presentación se deberá aportar aquellos datos e información relevante y significativa para el alumno, porque lo será igualmente para el 
tribunal, por ejemplo, aquellas experiencias que ha vivido, comprobado o evidenciado. Además, mas allá de reproducir lo que se haya aprendido, Brown y Glasner (2009) recomiendan relacionar ideas con conocimientos y experiencias previas, para así destacar principios importantes, mostrar que se han estudiado sus evidencias, que se han relacionado conclusiones, y que su propuesta tiene una lógica, una cuidada argumentación, y una postura crítica inteligente y creativa.

A continuación, expondremos el guión que recomendamos a nuestros estudiantes para sus exposiciones, y que tan buenos resultados les han reportado: 1) presentarse; 2) obtener la atención inmediata de los oyentes con un incidente, una noticia, un pensamiento o una experiencia que provoque interés y que esté relacionada con el tema; 3) destacar los puntos o aspectos más importantes de la exposición de forma sistematizada, ciñéndose a aquella información que considere relevante y que será evaluada por el tribunal; 4) incluir ejemplos y evidencias; 5) destacar el valor práctico, la utilidad o relevancia de lo que trata; 6) resumir lo expuesto; 7) cerrar la exposición con una buena conclusión.

Una vez organizada la presentación, el siguiente paso es ensayarla una y otra vez, teniendo en cuenta el tiempo y que no deben sobrepasarlo. Si se van a utilizar medios audiovisuales es esencial utilizar adecuadamente los colores, el tamaño de las letras y la cantidad de información que se ofrezca.

2) Fase de superación de la ansiedad y el miedo.

Teniendo en cuenta que hablar delante de un grupo de personas que no se conoce suele provocar cierto nivel de miedo, estrés o ansiedad, Vera (2009) recomienda, para cambiar esos pensamientos negativos que inundan la mente el que, momentos previos a una exposición, cuestionarnos esas ideas irracionales. Muchos estudiantes temen, por ejemplo, quedarse en blanco o equivocarse y que se rían de ellos. Por ello, la autora aconseja que la persona se pregunte por las consecuencias reales de esos temores, para que así sea consciente de la irracionalidad del miedo, y por ello, más realista, dando menos importancia a los posibles errores o problemas que surjan. Y es que, "uno de los medios más seguros de vencer el pánico a hablar en público es acumular una serie de experiencias afortunadas" (Carnegie, 2009:30), por ello, practicar a lo largo de toda su formación universitaria ayudará y preparará al estudiante para este tipo de experiencias. Aún así, lo normal es sentirse incómodos, sobre todo si nos van a evaluar, de manera que es muy recomendable que el estudiante aproveche cada oportunidad que surja en clase para exponer trabajos, hacer comentarios o participar en debates.

Para minimizar el nerviosismo que pueda provoca la defensa de un TFG o un TFM recomendamos los siguientes pensamientos, los cuales son sugeridos por psicólogos y expertos en oratoria: 1) no hay un trabajo perfecto, por lo que la exposición tampoco lo será, de manera que habrá que poner todo el esfuerzo y el entusiasmo posible para que salga lo mejor posible; 2) hay que tratar de no leer la mente de los miembros del tribunal, porque hará que perdamos naturalidad y entusiasmo; 3) los oyentes no suelen ser tan conscientes, como pudiéramos creer, del nivel de nerviosismo o miedo que sentimos; 4) si surgen temores y dudas no hay que intentar controlarlos $u$ obviarlos, hay que respirar hondo y sustituirlos por pensamientos reales y positivos; 5) ser conscientes de que puede que a algún miembro del tribunal no le guste la presentación, el tema, o ciertas ideas que se expongan, pero ese no es el objetivo, sino exponer un trabajo coherente, bien justificado y 
estructurado, que cumpla con los requisitos de evaluación; 6) aceptar de buen grado las recomendaciones y críticas, así como no justificarse; 7) previamente a la defensa es recomendable haber ensayado en el mismo lugar y, si no es posible, al menos haberlo visitado; 8) sonreír al hablar; 9) disfrutar de ese momento inusual que quizás no se repita nunca; 10) considerar esta actividad como una oportunidad más de entrenamiento para futuras experiencia profesionales y personales futuras.

3) Fase de exposición del trabajo:

La actitud con la que el estudiante afronte la defensa de su proyecto podrá ser un reflejo del resultado que obtenga, por ello, es aconsejable que afronte este reto con ilusión, dispuestos a hablar de su trabajo con pasión y entusiasmo, y a aprender de las recomendaciones que puedan hacerles.

a) Es recomendable que los estudiantes sonrían de forma sincera y oportunamente. Este acto los liberará de la tensión y los nervios, al mismo tiempo que hará más agradable la exposición al tribunal. Como oyentes, solemos ser más receptivos con una persona alegre y sonriente que con otra tensa, por lo tanto, es importante mostrar alegría sincera en la exposición.

b) Deberán expresarse de forma pausada, con calma, al mismo tiempo que con pasión, motivados y con argumentos sólidos. El objetivo es exponer de forma resumida su trabajo, por lo que hay que centrarse en lo más relevante y no intentar apresurarse a explicarlo todo, ya que para ello puede se hacer mención al trabajo escrito.

c) Mantener el contacto visual con todos los miembros del tribunal, no hacerlo es un indicio de temor e inseguridad. Si un estudiante observa que uno de ellos hace gestos que lo distraen o su cara expresa que no está de acuerdo con lo que expone, lo recomendable es no volver a mirarlo, ya que le perjudicará y hará que se cuestione mientras expone qué es lo que no le gusta, y puede que la persona en cuestión se sienta incómoda por un problema personal y no tenga nada que ver con la exposición.

d) Evitar cruzar los pies y los brazos, meter las manos en los bolsillos, caminar de un lado para otro sin sentido y posicionarse detrás de una mesa o una silla.

e) Ser conscientes de la situación y emplear un vocabulario más académico y formal. Aunque el estudiante puede utilizar un pequeño guión en su exposición hay que evitar estar leyéndolo. Tampoco es recomendable aprendérselo de memoria ni leer toda la información que se expone en las diapositivas.

f) La fase de preguntas finales y de recomendaciones no debe durar más de cinco minutos, por lo que es aconsejable que el alumno responda de forma clara y concisa a lo que se le ha preguntado. No debe extenderse, ya que puede que todo el trabajo realizado minutos antes se vea deslucido por un intento de destacar o entrar en debate con algunos de los miembros del tribunal. Es importante saber aceptar las críticas y los comentarios del tribunal sin ofenderse y de buen grado, ya que su objetivo no es el de hacer sentir mal al estudiante que presenta su trabajo, sino el de valorarlo de la mejor manera posible a través de preguntas y por su forma de responder. Ha habido estudiantes que se han ofendido ante las críticas o que han tratado de interrumpir a los miembros del tribunal para justificarse, y lo único que han logrado es que, a causa de los nervios, han dado una imagen de sí mismos que posiblemente no se corresponda con la realidad. 


\section{Conclusiones}

A lo largo del artículo hemos podido evidenciar la importancia de la expresión oral en el ámbito universitario para, por ejemplo, la defensa de los TFG y TFM. También, destacado, a partir de otros autores, la patente falta de formación del alumnado y sus dificultades para una adecuada comunicación, originados por temores e inseguridades. Por ello, quisiéramos reivindicar la necesidad de que los estudiantes se formen como excelentes comunicadores, sobre todo oralmente, bien a través de talleres, conferencias, cursos o asignaturas. A ser posible todo ello a los largo de los años que duren sus estudios, ya que no solo es necesario dominar la competencia comunicativa durante la etapa universitaria, sino también para el desarrollo personal y profesional del alumnado.

Para una adecuada evaluación es fundamental establecer criterios medibles a través de instrumentos adecuados, como por ejemplo, rúbricas, rejillas o listas de cotejo, o al menos mejorar los ya existentes (valorando aspectos como la creatividad o la actitud), y especificar en ese instrumento de evaluación qué implica cada uno de ellos. No hay que presuponer erróneamente que los estudiantes ya saben lo que hay que hacer. Por ejemplo, hay alumnos que desconocen qué implica exactamente el "uso del lenguaje corporal y la voz" en su defensa de TFG, o cómo demostrar ante el tribunal que tienen cierto "dominio y comprensión del tema", o bien tampoco saben cómo lograr que su exposición destaque por su "claridad, ritmo y organización". Por ello, los estudiantes necesitan saber con detalle cómo los valorará el tribunal a través de los diferentes criterios de evaluación. Por ejemplo, cuando se les valora por su "adecuada y pertinente argumentación ante las preguntas y comentarios de los y las miembros de la Comisión Evaluadora", se pueden imaginar a qué se refiere este aspecto, pero es necesario que sepan qué tipo de respuestas son las más adecuadas, y qué actitud deben tener para así lograr la más alta calificación.

En los "Cursos o" de la Universidad de Málaga solemos aconsejar a nuestros estudiantes que aprovechen cada oportunidad que se les presente en clase para participar, exponer trabajos o comentar en debates. Únicamente practicando podrán mejorar la expresión oral y superar sus miedos y temores. Además, es necesario que identifiquen sus limitaciones para así poder centrarse en mejorarlas, al mismo tiempo que se perfeccionan en otros aspectos. Teniendo en cuenta que los alumnos con una alta autoestima suelen exponer con más naturalidad, es necesario que aquellos otros estudiantes que aún no creen demasiado en sí mismos sean conscientes que pueden mejorar con la actitud adecuada, por ejemplo, valorando sus errores, no como una penalización, sino como una necesidad para seguir aprendiendo y mejorando.

En este sentido quisiéramos destacar la recomendación que hace Núñez (2002) para mejorar la competencia comunicativa en el aula, proponiendo que la enseñanza del lenguaje se base en: acometer la renovación de la antigua retórica (el arte de hablar en público); fomentar la lectura y el pensamiento crítico; dar un espacio en el aula a la radio; emplear la dramatización y el teatro como recurso didáctico que fomenten el uso cotidiano y formal del lenguaje y la imaginación; emplear la videocámara para analizar el trabajo en el aula; así como fomentar talleres de lengua y literatura.

Con este artículo pretendemos motivar y generar interés, tanto en docentes como en alumnos, de manera que la defensa de un TFG o TFM se convierta en una experiencia enriquecedora. Donde el tribunal valore de la forma mas real y objetiva posible el trabajo de cada alumno, y que los estudiantes, a través de sus motivadoras e interesantes exposiciones, disfruten compartiendo sus aprendizajes. 


\section{Bibliografía}

Bain, K. (2007). Lo que hacen los mejores profesores universitarios. Valencia: PUV.

Blanco, A. (Coord.) (2009). Desarrollo y evaluación de competencias en educación superior. Madrid: Narcea.

Brown, B. (2010). "El poder de la vulnerabilidad". [Video] TED Ideas Worth Spreading. Recuperado dehttp://www.ted.com/talks/brene_brown_on_vulnerability.html. (Consultado el 29/07/2014)

Brown, S. y Glasner, A. (Eds.) (2007). Evaluar en la universidad. Problemas y nuevos enfoques. Madrid: Narcea.

Burns, D. (2006). Adiós, ansiedad. Cómo superar la timidez, los miedos, las fobias y las situaciones de pánico. Barcelona: Paidós Ibérica.

Cassany, D. et al (1994). Enseñar Lengua (7ª ed.). Barcelona: Graó.

Carnegie, D. (2011). La comunicación: tu camino hacia el éxito. Barcelona: Obelisco.

Carnegie, D. (2009). El camino fácil y rápido para hablar eficazmente. Barcelona: Elipse.

Cebreiros, J. (2012). Ser feliz no implica ser idiotas. Madrid: Bubok Publishing.

Céster, A. (2013). El miedo escénico. Orígenes, causas y recursos para afrontarlo con éxito. Barcelona: Robin Books.

Ferrer, V., Carmona, M. y Soria, V. (Eds.) (2013). El trabajo Fin de Grado. Guía para docentes, estudiantes y agentes colaboradores. Madrid: McGraw-Hill.

García-Sanz, M.P. (2014). La evaluación de competencias en Educación Superior mediante rúbricas: un caso práctico. Revista Electrónica Interuniversitaria de Formación del Profesorado, 17 (1), 87-106.

Gauquelin, F. (1982). Saber comunicarse. Bilbao: Mensajero.

Girodo, M. (1997). Cómo vencer la timidez. Barcelona: Grijaldo.

Jaume-I-Capó, A., Guerrero, Miró y Egea, A. (2012). "Elaboración de una rúbrica para la evaluación TFG y TFM de informática en la Universitat de les Illes Balears". En L. Jiménez, G. (Ed.), Estrategias y herramientas para el aprendizaje y la evaluación (pp.17-24). Ciudad Real, España: Universidad de Castilla-La Mancha.

Knapp, M. (2010). La comunicación no verbal (10ª ed.). Barcelona: Paidós comunicación.

Núñez, G. (2002). La narración oral en la escuela. Almería: Servicio de Publicaciones de la Universidad de Almería.

Pinilla, R. et. al. (2012). "Concepciones y prácticas de los profesores sobre la evaluación de la oralidad". Enunciación, 17 (2), 56-74.

Recasens, M. (2003). Comprensión y expresión oral. Barcelona: Ceac.

Scheler, M. (2004). Sobre el pudor y el sentimiento de vergüenza. Salamanca: Ediciones Sígueme.

Vallejo-Nágera, J. (2007). Guía práctica de la psicología (11ª ed.). Madrid: Temas de hoy.

Vera, M. y Roldán, G. (2009). Ansiedad Social. Manual práctico para superar el miedo. Madrid: Pirámide. 
Vilà, M. et. al. (2005). El discurso oral formal. Contenidos de aprendizaje y secuencias didácticas. Barcelona: Graó.

Villanueva, J. (2013). "Competencia oral en alumnado universitario de educación". En Núñez P. (Ed.), Oralidad y educación (pp. 511-519). Granada, España: Universidad de Granada. 